$\overline{R e v i s t a ~ I b e r o a m e r i c a n a . ~}$ Vol. LXIV, Núms. 184-185, Julio-Diciembre 1998; 633-636

\title{
PARA LEER LA SONRISA DE MONTERROSO
}

POR

JUAN A. EPPLE

University of Oregon

Leído, antologado, imitado, citado, celebrado, pluralizado en ingeniosas versiones textuales, Augusto Monterroso (Tegucigalpa, 1921) es uno de los escritores más conocidos e influyentes de la literatura hispanoamericana contemporánea. Pero como suele ocurrir con aquellos creadores cuya obra transgrede los cánones y clasificaciones en uso, su consagración pública y su valoración crítica se han manifestado con cierta tardanza. Lo que por otra parte ha contribuído a resaltar sus merecimientos. En 1991 el Instituto de Cooperación Iberoamericana de España le dedicó una de sus "Semanas de Autor" y en 1996 le fue otorgado el prestigioso Premio de Literatura Latinoamericana y del Caribe Juan Rulfo. Ese mismo año Monterroso, radicado en México, regresó al país de su nacionalidad, tras 43 años de ausencia, para recibir el Doctorado Honoris Causa con que lo distinguió la Universidad de San Carlos de Guatemala.

Sus textos de ficción iniciales datan de 1952, con un primer conjunto narrativo consolidado en 1959, cuando publica Obras completas ( $y$ otros cuentos). El título ya hace presente la intención paródica que permeará su obra, pues se refiere al relato "Obras completas" incluído en el volumen. El corpus textual de Monterroso se expande luego en La Oveja negra (y demás fábulas) (1969), Movimiento perpetuo (1972), Lo demás es silencio (1978), La palabra mágica (1983), La letra e (1985), y Los buscadores de oro (1993). En 1996 el sello Alfaguara editó en un solo volumen la totalidad de sus cuentos, fábulas y su única novela.

El primer trabajo de acercamiento crítico a su obra fue el volumen monográfico Augusto Monterroso (1976), de la serie Cuadernos de Texto Crítico, coordinado por Jorge Ruffinelli. En 1988 Wilfredo H. Corral editó La literatura de Augusto Monterroso, (hay una segunda edición en prensa, con nuevos estudios), quien además tuvo a su cargo la edición de trabajos críticos y el dossier que le dedicara el Instituto de Cooperación Iberoamericana (publicaciones en prensa). A esta bibliografia básica se suman dos estudios monográficos: Lector, sociedad y género en Monterroso de Wilfredo H. Corral (México, 1985), y La fábula de Monterroso, lugar de encuentro con la verdad, de Lia Roux de Caicedo (Colombia, 1991).

La trampa en la sonrisa: sátira en la narrativa de Augusto Monterroso, de Francisca Noguerol Jiménez (Sevilla: Universidad de Sevilla, 1995) se distingue, a nuestro juicio, por ofrecer una caracterización integral de la obra del autor, haciéndose cargo de tres niveles de 
aproximación convincentemente concatenados: describe el desarrollo del trabajo creador de Augusto Monterroso desde sus comienzos, provee una indispensable contextualización histórico-cultural de esa obra y configura una exégesis de rango totalizador. Es un estudio que se destaca por su rigor analítico y por la claridad de la exposición, y donde - lo que es un rasgo poco común en la crítica académica de hoy- el ejercicio de erudición no se propone ostentar conocimientos literarios y familiaridad con determinadas teorías, sino que está al servicio de la comprensión cabal de los textos objeto de análisis. La diferenciación conceptual de las modalidades y géneros narrativos, de las estrategias de representación y simbolización discursivas, el cotejo filológico (tarea insoslayable para explicar las relaciones intertextuales y metatextuales de los relatos de Monterroso), y hasta el diálogo con la crítica especializada, se someten a la prueba de laboratorio del texto, que es el que en última instancia debe validar la propuesta interpretativa, y no a la inversa. Disposición metodológica cuya pertinencia es requerida, como un reto, por la extraordinaria variedad e inventiva de la narrativa de Monterroso, una obra que, como señalaba en 1983 Sabas Martín, diferenciándolo del promocionado grupo del boom latinoamericano, "es como un claro en la selva, como una isla con fronteras propias", y cuyo carácter innovador respecto a la tradición de la prosa breve la distingue como un "laboratorio de la narración", al decir de Carlos Rincón.

El libro está organizado en cuatro capítulos: "En torno al concepto de sátira", "Augusto Monterroso y su tiempo", "Sátira en la narrativa de Monterroso" y "Formalización del ataque satírico".

Incluye además una completa bibliografía de y sobre el autor, apartado que de por sí le otorga al libro una utilidad adicional como referencia.

A partir de una revisión sistemática del concepto moderno de sátira que ha ido discerniendo en particular la crítica anglosajona (Louis Anderson, Wayne Booth, Gerald L. Bruns, Lionel Duisit, Robert Elliot, Leonard Feinberg, Alastair Fowler, Northrop Frye, Ellen Douglas Leyburn, Linda Hutcheon, Margaret A. Rose y Arthur Pollard), Francisca Noguerol adopta una concepción de amplitud más operativa que prescriptiva, entendiéndolo como un modo de discurso que somete a una crítica radical los fundamentos sociales y éticos del mundo contemporáneo, pero que renuncia a proponer normas correctivas o moralizadoras. Esta postura radical orienta los sentidos subsidiarios que tienen en la obra de Monterroso otros modos expresivos como la ironía, la parodia, la alegoría, el humor, el ludismo y la caricatura. Es decir, en esta jerarquización, la carga satírica como categoría rectora del universo simbólico relativiza los parámetros de codificación autosuficientes de los otros modos, que devienen así en opciones técnicas o estrategias retóricas.

De aquí que a Noguerol le resulte consecuente — pero también problemáticoconcluir que esta acentuada postura satírica canaliza una visión escéptica del mundo:

La narrativa de Monterroso presenta una visión escéptica y pesimista de la condición humana. Refleja el fracaso del hombre en todos los planos de su existencia y cuestiona la validez de su descripción como el eslabón más perfecto en la escala de la evolución animal. Pone en solfa este concepto demostrando que la inteligencia humana se ha encontrado más veces al servicio de la destrucción que de la labor creadora (54). 
Pero - y esto lo señala la autora en las secciones dedicadas al análisis de las distintas estrategias compositivas- si la intención artística de sus textos no se satisface en la crítica de situaciones específicas sino que buscan modificar el "horizonte de expectativas" del lector, ampliando las posibilidades de exégesis de la lectura, entonces ese escepticismo es también relativo. O dicho de otro modo: lo que salva su postura de una conotación de "escepticismo" es un sustrasto ético que está en la base de su operación creadora: la duda metódica al servicio de la desautomatización de nuestros códigos culturales. Como señalaba Mansoliver (citado por Noguerol): "lo único que acepta ser expresado axiomáticamente es la duda" (54). De ahí que —como bien destaca la autora - sus textos se caractericen por su impronta palimpséstica, potenciadora de lecturas y sentidos diversos, y que sus modalidades preferidas sean la parodia y la ironía volcadas al universo metaficcional de los textos. Actitud distanciadora que busca provocar un efecto de "extrañeza" (Umberto Eco, David Bennet) y que lo acercan a la concepción posmodernista del arte. Pero sin su nihilismo. Por otra parte, el hecho de que esta obra concite una atención lectora tan entusiasta $-\mathrm{y}$ la apasionada exégesis de una joven investigadora - desestiman (o someten también a duda) esa validación pesimista.

Es perceptible, en verdad, cierto sustrato estoico en la burla de este satirista, que una lectora de tradición andaluza no podría menos que poner de relieve. Pero si bien este temple anímico lo acerca en ocasiones al escepticismo, su postura crítica busca esclarecer zonas salvadoras en su trato con lo humano.

En esta propuesta de interpretación globalizadora sobresale el exhaustivo análisis de la novela Lo demás es silencio (la vida y obra de Eduardo Torres) (1978), ese espléndido texto polifónico donde Monterroso confronta paródicamente las falacias "eruditas" del intelectual provinciano con ínfulas europeizantes - aquel que Lihn caracterizó como un "meteco"-, los códigos fosilizados de lectura e incluso y las trampas del discurso crítico. La autora, pesquisando justamente estas "trampas" compositivas en la estructura metatextual de la novela, define el sentido crítico que subyace en el tejido aparentemente liviano del collage narrativo. Aquí Monterroso encuentra a su lector "cómplice": aquél que puede percibir, con un riguroso trabajo de erudición aplicada, las bromas, los guiños, las alusiones, los sobreentendidos, las lecciones cifradas bajo el entramado aparentemente burlesco, de simple "divertimento", de la con-fabulación textual.

En suma, esta investigación monográfica discierne y analiza con perspicacia la pluralidad de lecturas codificadas en el estatuto palimpséstico de la narrativa monterrosiana. La mirada crítica de la investigadora se concentra en des-cubrir, descorriendo los «tupidos velos» donosianos o auscultando los reversos de la página, la dinámica de referentes humanos a que apelaba Monterroso cuando se refería (en La letra e) a los individuos que convocaba su escritura: "Yo soy ellos, que me ven y a la vez son yo, de este lado de la página o del otro, enfrentados al mismo fin inmediato: conocernos, y aceptarnos o negarnos; seguir juntos, o decirnos resueltamente adiós".

La lectura interpretativa de Francisca Noguerol no sólo contribuye a validar la relevancia y originalidad de Augusto Monterroso en las letras latinoamericanas, sino que "resitúa" convincentemente su obra en los dilemas que ocupan a la creatividad de fin de siglo. Una obra que, como lo demuestra en su estudio, 
se engloba plenamente en la estética contemporánea, en un nuevo marco ideológico caracterizado por la disolución de las normas estéticas clásicas y, específicamente, por la eliminación del concepto de decoro. Se adecúa a las características de la obra posmoderna porque presenta los rasgos definitorios de esta corriente estética, sintetizados en el desplazamiento genérico y discursivo, la crítica de los discursos de autoridad, la disolución de las narrativas legitimizadas, el escepticismo, la heterodoxia (religiosa y política), el eclecticismo, la exigencia de la participación activa del lector en la obra, el pluralismo, el "collage", la utilización de la cultura de masas, el "pastiche", la conciencia de la inutilidad de la literatura, el saber enciclopédico y el recurso continuo a la transtextualidad (228).

Finalmente, La trampa y la sonrisa aporta al estudio de la ficción latinoamericana una base de apoyo teórico adicional, al hacerse cargo del haz de procedimientos narrativos más recurrentes en el género del micro-relato. Francisca Noguerol es sin duda la especialista más destacada en esta importante modalidad discursiva de la literatura hispanoamericana, habiéndole dedicado ya siete ensayos: "El micro-relato latinoamericano: cuando la brevedad noquea", Lucanor 8, (1992); "Inversión de los mitos en el micro-relato hispanoamericano contemporáneo", Luis Gómez Canseco, ed. Las formas del mito en las literaturas hispánicas del siglo XX, (1994), "Humor e ironía en el micro-relato guatemalteco contemporáneo", Nueva Narrativa, Guatemala(1995), "Micro-relato argentino: entre la reflexión y el juego", Río de la Plata 15-16 (1996), "Evolución del micro-relato hispanoamericano (19601990)", Paco Tovar, ed. Narrativa y poesía hispanoamericana (1964-1994) Universidad de Lérida, (1996) y "Micro-relato y Posmodernidad: textos nuevos para un final de milenio", Revista Interamericana de Bibliografia, XLVI, 1 (1996).

Son ensayos que confluyen con naturalidad hacia un necesario proyecto de investigación monográfica que debe hacerle justicia a un género cuya vitalidad y apertura creadoras atraen una atención crítica cada vez más amplia, como se evidencia en el número especial que le dedica la Revista Interamericana de Bibliografia (Vol. XLVI, 1996) y en la realización del Primer Congreso Internacional de Minificción organizado por la Universidad Autónoma Metropolitana de México en agosto de este año.

En este libro dedicado a Monterroso, Francisca Noguerol se compromete a realizar esa nueva tarea y a compartir sus hallazgos de lectura con la cofradía de los que se reconocen en el bien o el mal común de la literatura, ese "ocio increíble del que somos capaces". 